\title{
Water Injection Fracture Pressure and Fracture Propagation Investigating in Poorly Consolidated Sandstone
}

\author{
A. Fan Baitao, B. Deng Jingen, C. Lin Hai, D. Sun Jin, and E. Li Jin
}

\begin{abstract}
Predictions of fracture initiation and propagation pressure are an essential prerequisite to determine reasonable injection pressure for poorly consolidated sandstone. Most models for hydraulic fracturing based on elasticity mechanics are not applicable for poorly consolidated rocks. The fluid-solid coupling model based on elastic theory of porous media for poorly consolidated sandstone is established to analyze fracturing modes and fracture initiation pressure by adopting the maximum tensile stress criterion and the Mohr-Coulomb criterion, and the calculation methods of water injection fracture pressure and water injection fracture propagation pressure are obtained in this paper. The study shows that fractures are mainly caused by shear failure and propagation direction is parallel to the maximum horizontal stress. The vertical and tangential effective stress are reduced with the increase of bottom-hole injection pressure. But the radial effective stress is just the opposite. So the transformation of the three principal effective stress values will occur with the increase of water injection pressure. The fractures paralleled to the radial direction of borehole are more easily propagate to formation interior when radial stress becomes intermediate principal stress. The work provides important guidance to determine the construction parameters micro-fracturing in water injection wells.
\end{abstract}

Index Terms-Poorly consolidated sandstone, water injection fracturing pressure, fracture propagation pressure, fracturing mode.

\section{INTRODUCTION}

Poorly consolidated sandstone reservoirs are common all over the world, such as USA Wilmington oilfield , Canada Athaska oilfield, Bohai oilfield, Dagang oil field of China [1]-[3]. Bohai oilfield that the main production area of CNOOC has explored and developed in poorly consolidated sandstone reservoirs. Water injection has become a key measure to improve well productivity and oil recovery in poorly consolidated sandstone reservoir. Poorly consolidated sandstone has the characteristics of shallow

Manuscript received February 18, 2018; revised March 30, 2018.

Fan Baitao is with China National Offshore Oil Corporation (CNOOC), senior engineer, the manager of department of well construction and intervention in Bohai Petroleum Administration Bureau in Tianjin, China.

Deng Jingen is with China University of Petroleum (Beijing), Department of Petroleum Engineering, Beijing, China. Meanwhile, he is the director of CNPC well stability laboratory, the director of Science and Technology Department of China University of Petroleum (Beijing).

Lin Hai is with China National Offshore Oil Corporation (CNOOC), Bohai research institute of Bohai Petroleum Administration Bureau in Tianjin, China (email: linhai2007021317@sina.com)

Sun Jin is with Institute of Deep-sea Science and Engineering, Chinese Academy of Sciences since 2016 in Sanya, China.

$\mathrm{Li}$ Jin is with Bohai research institute in Tianjin, China. buried depth, weak compaction, high pore and high permeability, poor cementation. Injection pressure will increase with the increase of water injection time [4], [5]. Oil production was got badly affected.Acidification is long-term conventional method adopted to plugging-removal of water injection wells in Bohai oilfield, but blockage removal effect is not ideal, due to the limitation of acidification validity period. Bohai oilfield has put forward the plugging-removal technology of micro-fracturing. It uses the injected water as fracturing fluid. The technology can increase bottom hole pressure near the wellbore to form micro-fracture through mud pump or fracturing pump pressure to achieve the purpose of augmenting injection and plugging removal without the use of tackifier and proppant. During the process of injecting water, high water injection pressure may lead to a series of safety problems [6], [7], injected water jumped into caprocks or interlaminar collusion [8], even fault rupture and leakage caused by injected water. Injection pressure should be in a reasonable range. The principle is to guarantee purpose of plugging-removal, to ensure the safety and oil reservoir development effect in the process of water injection. Therefore, the calculation of critical water injection pressure is the key factor.

Until now, the calculation of critical water injection pressure mainly focused on the brittle formation. It also considered fracture pressure of reservoir as the upper limit of water injection pressure [9]. The key to determine critical water injection pressure is accurately calculating the reservoir fracture pressure. In recent decades, many scholars have put forward different prediction models of fracture pressure, which were mainly based on preventing the formation from tensile fracture. The inflection point method of water injection instruction curve can roughly determine critical water injection pressure by analyzing instruction curve shape of water injection wellhead. The method was just used to qualitatively analyze fracture pressure [10], [11]. Fracture pressure gradient method was simple, but the reservoir fracture pressure by fracturing test was not equal to water injection fracture pressure. It cannot accurately reflect the water injection fracture pressure value [12], [13]. For new blocks without carrying out fracturing operations, fracture pressure prediction methods were adopted to determine the upper limit of bottom hole water injection pressure, such as Eaton method, Stephen method, H R method, Holbrook method, etc [14], [15]. These methods were based on the traditional linear elastic model of brittle formation. It think the cracks were caused by the tensile failure. Actually, Because of low strength and large plastic deformation, the traditional fracturing model are not 
applicable for poorly consolidated sandstone (low cohesive force, strong plasticity, high porosity and permeability). Li established the fracture pressure calculation model considering the reservoir pollution, but lacking of rigorous mechanics theory support [16]. Sun considered the effect of reservoir temperature and plugging degree on water injection fracture pressure, but the adaptability also need to be further evaluated [17].

It is different that the failure forms of consolidated sandstone from poorly consolidated sand with high pore-permeability. The fluid-solid coupling model of poorly consolidated sandstone was established and the calculation methods of water fracture pressure and fracture propagation pressure were put forward in this paper by comprehensively analyzing mechanical and physical properties of poorly consolidated sands.

\section{Fracture INITIATION PRESSURE MODEL OF UNCONSOLIDATED SANDSTONE IN INJECTED WELLS}

Although the initiation fracture models based on poroelastic theory are convenient to be used and can give reasonable prediction for hard rock formation [18], [19].

It's not applicable of these models to the description of fracture initiation in soft rocks due to the low cohesion and strength. Shear failure, plastic yield deformation and fluid-solid coupling effect of fracture tip are essential to the initiation and propagation of fractures. Many laboratory studies have shown that fractures in soft rocks was generated by fluid injection are very different from that in brittle hard rocks. Khodaverdian [20] found that the fracture morphology in unconsolidated sand is quite different from conventional tensile fractures observed in hard rocks, based on their experiments. The fractures in unconsolidated sandstone are more similar to the high-pore and high-permeability zone. The fractures are more likely caused by shear failure. Pater [21] found that in-situ stress and fluid rheology have a strong influence on the initiation and propagation of fractures. The results show shear fractures are more likely to be easily generated at high confining stress. Due to the particularity of unconsolidated sand, the initiation and propagation of fractures are different from those of ordinary medium and high strength sand. In view of this, the fluid-solid coupling model of unconsolidated sandstone is established to analyze the stress state and failure modes in the process of water injection.

\section{A. Basic Assumptions of the Model}

The model mainly includes the following five basic assumptions:

1) Coupling system is composed of solid skeleton and single-phase fluid. Fluid completely fills the pore space. Rock is linear elastic medium. Fluid flow is conform to Darcy law.

2) Oil saturation around the injection wells is the residual oil saturation, namely the single-phase seepage around injection wells.

3) Rock density, fluid viscosity and density are uniformly distributed in the formation.

4) Rock tensile failure conforms to the maximum tensile stress criterion. Shear failure conforms to Mohr -
Coulomb strength criterion.

5) Considering fluid compressibility

\section{B. Governing Equations}

The stress components of any element in rock meet static equilibrium conditions. The balance differential equation in three-dimensional cylindrical coordinate system is expressed as:

$$
\left\{\begin{array}{l}
\frac{\partial \sigma_{r}}{\partial r}+\frac{\partial \sigma_{\theta r}}{r \partial \theta}+\frac{\partial \sigma_{z r}}{\partial z}+\frac{\sigma_{r}-\sigma_{\theta}}{r}=0 \\
\frac{\partial \sigma_{\theta r}}{\partial r}+\frac{\partial \sigma_{\theta}}{r \partial \theta}+\frac{\partial \sigma_{\theta r}}{\partial z}+\frac{2 \sigma_{r \theta}}{r}=0 \\
\frac{\partial \sigma_{z r}}{\partial r}+\frac{\partial \sigma_{z \theta}}{r \partial \theta}+\frac{\partial \sigma_{z}}{\partial z}+\frac{\sigma_{z r}}{r}=0
\end{array}\right.
$$

where $\sigma_{r}, \sigma_{\theta}$ and $\sigma_{z}$ are radial stress, tangential stress and vertical stress, respectively, Pa. $\sigma_{\theta r}, \sigma_{z r}$ and $\sigma_{z \theta}$ are the shear stress, $\mathrm{Pa}$.

Fluid mass conservation equation, Darcy's law and compression equation, Percolation continuity equation under passive unsteady state can be represented as:

$$
\frac{\partial(\phi \mu c p)}{\partial t}=\nabla \cdot(k \nabla p)=\frac{1}{r} \frac{\partial}{\partial r}\left(k r \frac{\partial p}{\partial r}\right)+\frac{1}{r^{2}} \frac{\partial}{\partial \theta}\left(k \frac{\partial p}{\partial \theta}\right)
$$

where $\phi$ is the porosity. $\mu$ is the fluid dynamic viscosity, Pa.s. $C$ is compressibility of the fluid, $\mathrm{Pa}^{-1} . k$ is the permeability, $\mathrm{m}^{2}$. $\quad p$ is formation pore pressure, $\mathrm{Pa}$.

The constitutive equation of elastic porous medium can be written as:

$$
\sigma_{i j}^{\prime}=-\lambda \varepsilon_{v} \delta_{i j}-2 G \varepsilon_{i j}
$$

where $\sigma_{i j}^{\prime}$ is effective stress tensor, Pa. $\lambda$ is Lame coefficient, $\lambda=\frac{E v}{(1+v)(1-2 v)}$, where $E$ is the elastic modulus, Pa. $v$ is poisson's ratio. $G$ is shear modulus, $\mathrm{Pa}$. $\varepsilon_{v}$ is volumetric strain. $\varepsilon_{i j}$ is strain tensor. $\delta_{i j}$ is Konecker symbol.

The geometric equations of cylindrical coordinates can be written as

$$
\begin{gathered}
\varepsilon_{r}=\frac{\partial u}{\partial r} \quad \varepsilon_{\theta}=\frac{u}{r}+\frac{\partial v}{r \partial \theta} \quad \varepsilon_{z}=\frac{\partial w}{\partial z} \\
\varepsilon_{r \theta}=\frac{1}{2}\left(\frac{\partial v}{\partial r}-\frac{v}{r}+\frac{\partial u}{r \partial \theta}\right) \quad \varepsilon_{\theta z}=\frac{1}{2}\left(\frac{\partial w}{r \partial \theta}+\frac{\partial u}{\partial z}\right) \\
\varepsilon_{z r}=\frac{1}{2}\left(\frac{\partial w}{\partial r}+\frac{\partial u}{\partial z}\right)
\end{gathered}
$$

where $u, v$ and $w$ is radial displacement, tangential displacement and vertical displacement, respectively, m. $\varepsilon_{r}$, $\varepsilon_{\theta}$ and $\varepsilon_{z}$ is radial strain, tangential strain and vertical strain, respectively.

Strength failure criterion: When the stress state of rock 
meet (6), the formation rock will present tensile failure:

$$
\sigma_{3}^{\prime}=-\sigma_{t}
$$

where $\sigma_{3}^{\prime}$ is the minimum effective stress, Pa. $\sigma_{t}$ is the tensile strength, Pa.

When the stress state of rock meet (7) (Mohr-Coulomb strength criterion), the formation rock will present shear failure:

$$
\sigma_{1}^{\prime}=\sigma_{3}^{\prime} \frac{1+\sin \varphi}{1-\sin \varphi}+2 C \sqrt{\frac{1+\sin \varphi}{1-\sin \varphi}}
$$

where $\sigma_{1}^{\prime}$ and $\sigma_{3}^{\prime}$ are the maximum and minimum principal effective stresses, respectively, $\mathrm{Pa}$. $C$ is cohesive. $\varphi$ is the internal friction angle, ${ }^{\circ}$.

\section{Boundary and Initial Conditions}

The mechanical model established in this paper is plane-strain model. Inner boundary and outer boundary are circular boundary. Then, the inner and outer boundary conditions include the stress boundary conditions and corresponding pore pressure boundary conditions. The model considers non-uniform in-situ stress. The inner and outer boundary conditions can be given by transformation of coordinates.

(1) The inner boundary conditions are

$$
\left\{\begin{array}{l}
\left.p\right|_{r=r_{w}}=p_{w} \\
\left.\sigma_{r}^{\prime}\right|_{r_{w}}=(1-\alpha) p_{w} \\
\left.\sigma_{r \theta}^{\prime}\right|_{r=r_{w}}=0
\end{array}\right.
$$

where $\alpha$ is Biot coefficient., $p_{w}$ is bottom hole fluid pressure, $\mathrm{Pa}$.

(2) The outer boundary conditions are

$$
\left\{\begin{array}{l}
\left.p\right|_{r=r_{e}}=p_{0} \\
\left.\sigma_{r}^{\prime}\right|_{r=r_{e}}=\frac{\sigma_{x}+\sigma_{y}}{2}+\frac{\sigma_{x}-\sigma_{y}}{2} \cos 2 \theta-\alpha p_{0} \\
\left.\sigma_{r \theta}^{\prime}\right|_{r=r_{e}}=\frac{\sigma_{y}-\sigma_{x}}{2} \sin 2 \theta
\end{array}\right.
$$

where $\sigma_{x}$ and $\sigma_{y}$ are two horizontal principal stress, $\mathrm{Pa}$. $p_{0}$ is original formation pore pressure, $\mathrm{Pa}$.

The initial pore pressure conditions are expressed as:

$$
\left.p\right|_{t=0}=p_{0}
$$

(1) to (10) are the fracture propagation pressure calculation model of poorly consolidation sandstone under the condition of water injection.

\section{Solution Method for the Model}

Due to the symmetry of the model, this paper adopts a quarter model. Using the finite difference method and geometric progression grids to discrete the governing equations and boundary conditions. Then the radial coordinate $r$ is converted into rectangular coordinates $x$. It can be written as (11)

$$
x=\ln \left(\frac{r}{r_{w}}\right)
$$

For plane strain problem, the stress equilibrium equations and implicit difference scheme of percolation continuity equation after discrete are expressed in related references.

Two straight flange boundaries are also included. Stress boundary conditions expressed by displacement boundary conditions are given as:

(1) The inner boundary conditions are

$$
\begin{gathered}
\left.p\right|_{r=r_{w}}=p_{w} \\
\left.\sigma_{r}\right|_{r=r_{w}}=-(\lambda+2 G) \frac{1}{r} \frac{\partial u}{\partial x}-\left.\lambda\left(\frac{u}{r}+\frac{\partial v}{r \partial \theta}\right)\right|_{r=r_{w}}=(1-\alpha) p_{w} \\
\left.\sigma_{r \theta}\right|_{r=r_{w}}=-\left.G\left(\frac{\partial v}{\partial r}-\frac{v}{r}+\frac{\partial u}{r \partial \theta}\right)\right|_{r=r_{w}}=0
\end{gathered}
$$

(2) The outer boundary conditions are

$$
\begin{gathered}
\left.p\right|_{r=r_{e}}=p_{0} \\
\left.\sigma_{r}^{\prime}\right|_{r=r_{w}}=-(\lambda+2 G) \frac{1}{r} \frac{\partial u}{\partial x}-\left.\lambda\left(\frac{u}{r}+\frac{\partial v}{r \partial \theta}\right)\right|_{r=r_{w}}=\frac{\sigma_{x}+\sigma_{y}}{2}+\frac{\sigma_{x}-\sigma_{y}}{2} \cos 2 \theta-\alpha p_{0} \\
\left.\sigma_{r \theta}^{\prime}\right|_{r=r_{w}}=-\left.G\left(\frac{\partial v}{\partial r}-\frac{v}{r}+\frac{\partial u}{r \partial \theta}\right)\right|_{r=r_{w}}=\frac{\sigma_{y}-\sigma_{x}}{2} \sin 2 \theta
\end{gathered}
$$

Because of the symmetry of the model, two straight flange boundaries are exerted by artificial boundary

\begin{tabular}{|c|c|c|c|}
\hline Parameter name & Value & Parameter name & Value \\
\hline $\begin{array}{l}\text { Elasticity modulus } \\
/ \mathrm{GPa}\end{array}$ & 1 & Poisson's ratio & 0.27 \\
\hline $\begin{array}{c}\text { Maximum } \\
\text { horizontal principal } \\
\text { stress } / \mathrm{MPa}\end{array}$ & 27 & $\begin{array}{l}\text { Minimum horizontal } \\
\text { principal stress /MPa }\end{array}$ & 24 \\
\hline Vertical stress /MPa & 30 & Biot coefficient & 0.9 \\
\hline $\begin{array}{l}\text { Water compression } \\
\text { coefficient /MPa-1 }\end{array}$ & 0.0005 & $\begin{array}{c}\text { Original pore pressure } \\
\text { /MPa }\end{array}$ & 15 \\
\hline Porosity & 0.25 & permeability /mD & 1000 \\
\hline $\begin{array}{l}\text { Water viscosity } \\
\text { /mPa.s }\end{array}$ & 1 & Water density /kg/m3 & 1000 \\
\hline $\begin{array}{c}\text { Internal friction } \\
\text { angle } /^{\circ}\end{array}$ & 30 & $\begin{array}{l}\text { Formation outer } \\
\text { boundary /m }\end{array}$ & 10 \\
\hline Cohesion /MPa & 0.3 & uniaxial compressive & 1 \\
\hline
\end{tabular}
condition, namely (18)- (19).

$$
\begin{aligned}
& \left.v\right|_{\theta=0}=0 \\
& \left.v\right|_{\theta=\pi / 2}=0
\end{aligned}
$$

\section{WAter InJeCtion Fracture Pressure CALCUlation OF POORLY CONSOLIDATED SAND}

Taking the mechanical and physical properties of poorly consolidated sands in Bohai oilfield for an example to calculate water injection fracture pressure and fracture propagation pressure. The parameters are shown in Table I. Wellbore diameter is $16.51 \mathrm{~cm}$. 
A. The Effective Stress State and Stress Path Analysis on Minimum and Maximum Horizontal Principal Stress Orientation

Choosing different bottom-hole pressure of water injection well to calculate the effective stress distribution near wellbore by the fluid-structure coupling model established in paper, $18 \mathrm{MPa}, 22 \mathrm{MPa}, 25 \mathrm{MPa}$ respectively. Fig. 1 and Fig. 2 show stress calculation results on minimum and maximum horizontal principal stress orientation.

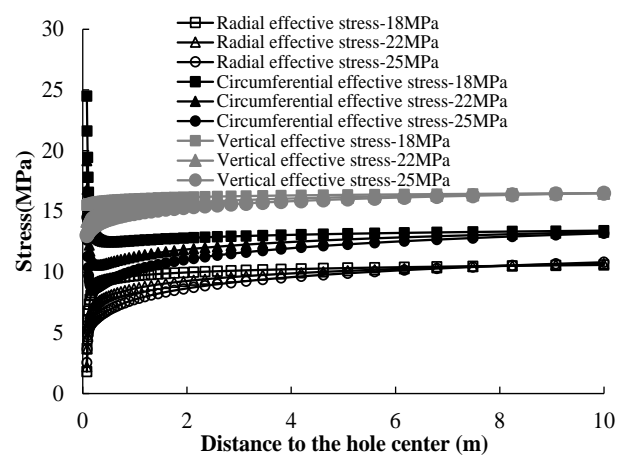

Fig. 1. The distribution of radial, tangential and vertical effective stress on minimum horizontal stress orientation.

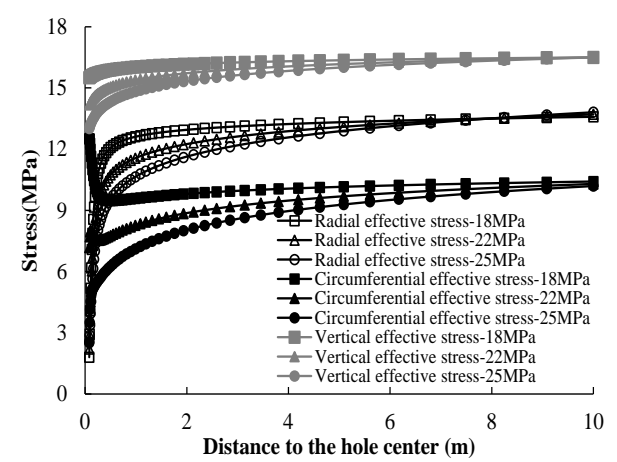

Fig. 2. The distribution of radial, tangential and vertical effective stress on maximum horizontal stress orientation.

Fig. 1 and Fig. 2 show that formation pore pressure was rising and effective stress was reduced with the increase of water injection pressure (Radial stress near wellbore was rising with the increase of water injection pressure, but was reducing away from the wellbore). Water injection is equal to the unloading process, only reduced degrees of each stress was different, namely different water injection pressure will result in relative changes of the three effective principal stress. The change of three main effective stress near borehole was shown in Fig. 3 and Fig. 4.

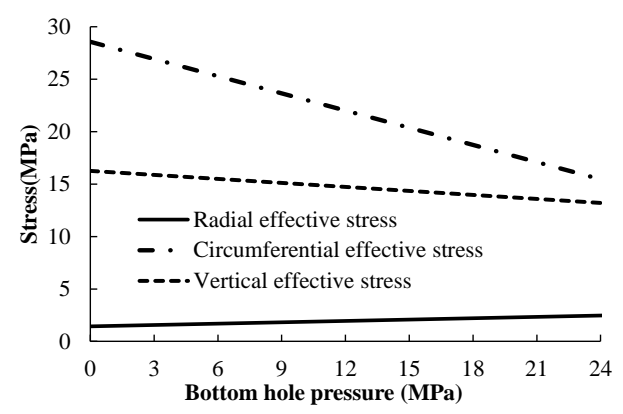

Fig. 3. The relative value of effective stress near wellbore on minimum horizontal stress orientation.

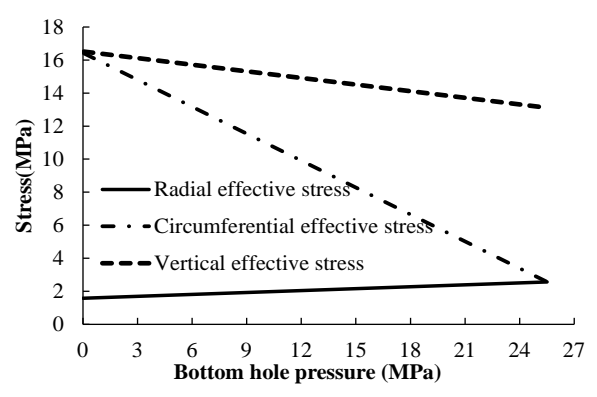

Fig. 4. The relative value of effective stress near wellbore on maximum horizontal stress orientation.

Fig. 3 and Fig. 4 show that vertical and tangential effective stress are reduced, but radial effective stress is rising with the increase of bottom hole pressure of water injection wells both the maximum and minimum horizontal stress orientation.

The relative value of three effective principal stresses was $\sigma_{\theta}^{\prime}>\sigma_{v}^{\prime}>\sigma_{r}^{\prime}$ on the minimum horizontal stress orientation when bottom-hole pressure was less than 25.5 MPa. The relative value of three effective principal stresses on the maximum horizontal stress orientation was changed from $\sigma_{v}^{\prime}>\sigma_{\theta}^{\prime}>\sigma_{r}^{\prime}$ to $\sigma_{v}^{\prime}>\sigma_{r}^{\prime}>\sigma_{\theta}^{\prime}$ when bottom-hole pressure was $25.5 \mathrm{MPa}$. The radial effective stress became the intermediate principal stress. The tangential stress became the minimum principal stress. The change of stress state will impact fracture morphology of poorly consolidated sandstone.

\section{B. The Conditions of Fracture Initiation and Propagation of Poorly Consolidated Sandstone}

The fracture of poorly consolidated sandstone may be caused by tensile failure or shear failure. It depends on the stress path.

1) Tensile failure: When (6) is satisfied, namely, the maximum tensile stress more than rock tensile strength, the tensile fracture is induced. The fracture plane is perpendicular to the minor principal stress $\sigma_{3}^{\prime}$.

2) Shear failure: When. (7) is satisfied, the shear fracture is induced. In addition, the shear plane induced by shear failure has a certain direction. The conjugate shear plane that shear angle is approximately $\gamma=45^{\circ}-\varphi / 2$ will be formed when shear failure is induced according to Mohr - coulomb strength criterion. The conjugate shear plane is parallel to the intermediate principal stress. The stress concentration is around the borehole, particularly in the maximum and minimum horizontal stress direction. The three principal stresses are vertical stress $\sigma_{v}^{\prime}$, tangential stress $\sigma_{\theta}^{\prime}$ and radial stress $\sigma_{r}^{\prime}$ respectively. Obviously, the fractures paralleled to the radial direction of borehole are more easily propagated when radial stress is the intermediate principal stress. At this time, the fracture that is different from fractures created hydraulic fracturing in conventionally consolidated and brittle rocks is high porosity and permeability zone. Fig. 5 is the geometrical morphology diagram of conjugate shear plane caused by shear failure under different relative values of principal stress around the borehole. 


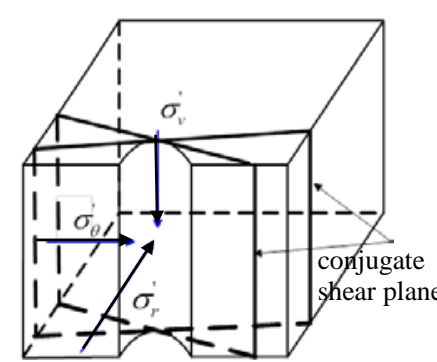

(a) $\sigma_{\theta}^{\prime}>\sigma_{v}^{\prime}>\sigma_{r}^{\prime}$

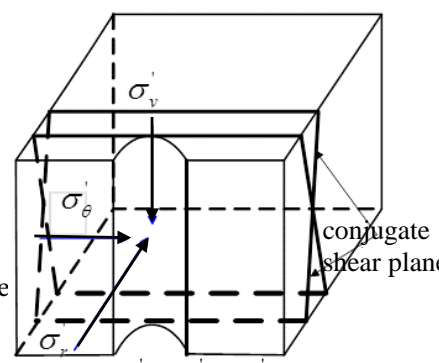

(b) $\sigma_{v}^{\prime}>\sigma_{\theta}^{\prime}>\sigma_{r}^{\prime}$

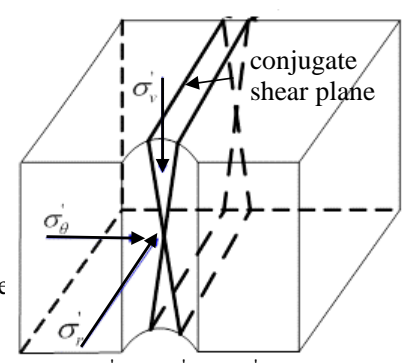

(c) $\sigma_{v}^{\prime}>\sigma_{r}^{\prime}>\sigma_{\theta}^{\prime}$

Fig. 5. The geometrical diagram of conjugate shear plane under different relative values of principal stress around the borehole.

As shown in Fig. 5, when the intermediate principal stress is $\sigma_{v}^{\prime}$ or $\sigma_{\theta}^{\prime}$, the conjugate shear plane around borehole prevented the propagation of injected water in the radial direction. The fractures are quite difficult to propagate to the formation interior. However, when the intermediate principal stress is $\sigma_{r}^{\prime}$, the propagation direction of conjugate shear plane is radial, which is advantageous for fracture propagation to the formation interior. Therefore, the form of shear fracture in poorly consolidated sandstone should meet the following two conditions: Rocks are subjected to shear failure surrounding borehole. Radial effective stress is the intermediate principal stress.

$C$ The calculation of water injection fracture and fracture propagation pressure

Calculated stress state around borehole was substitute into Mohr-Coulomb strength criterion. Shear failure firstly happened both maximum and minimum horizontal stress orientation. Tensile failure did not occur. This indicates that the fractures are mainly caused by shear failure in poorly consolidated sandstone. The results are consistent with the abroad research results. Fig. 3 and Fig. 4 show that the vertical stress is intermediate principal stress on the horizontal stress orientation, the fracture is quite difficult to propagate to the formation interior. The radial stress is intermediate principal stress when the bottom hole pressure reaches $25.5 \mathrm{MPa}$ on the maximum horizontal stress orientation. The conjugate shear plane is shown in Fig. 5(c). The fractures are more easily to propagate to the formation interior. The bottom hole pressure 25.5 MPa is the water injection fracture pressure. The vertical and radial effective stress should satisfy (20).

$$
\sigma_{v}^{\prime}=\sigma_{\theta}^{\prime} \frac{1+\sin \varphi}{1-\sin \varphi}+2 C \sqrt{\frac{1+\sin \varphi}{1-\sin \varphi}}
$$

The stress state far away from borehole is the original in-situ stress. The water will permeate into the surrounding formation through fractures in process of injecting water. It will form the high pressure zone at the fracture tip and reduce the effective stress. The fracture propagation should satisfy Mohr-Coulomb strength criterion. It is expressed as (21)

$$
\sigma_{v}-\alpha p=\left(\sigma_{h}-\alpha p\right) \frac{1+\sin \varphi}{1-\sin \varphi}+2 C \sqrt{\frac{1+\sin \varphi}{1-\sin \varphi}}
$$

where $p$ is the pressure at the fracture tip, $\mathrm{Pa}$.

Water injection fracture propagation pressure is expressed as (22)

$$
p=\frac{\sigma_{h} \frac{1+\sin \varphi}{1-\sin \varphi}+2 C \sqrt{\frac{1+\sin \varphi}{1-\sin \varphi}}-\sigma_{v}}{\alpha\left(\frac{1+\sin \varphi}{1-\sin \varphi}-1\right)}
$$

Table I model parameters were used. The fracture propagation pressure calculated by (22) is $22.6 \mathrm{MPa}$, 23.9MPa and 25.3 MPa accordingly when the Biot coefficient is $0.95,0.9$ and 0.85 respectively. That is, The smaller Biot coefficient is, the fracture propagation pressure is higher,. The fractures are more difficult to extend. Noticing the point that the fracture propagation pressure is not the bottom hole pressure of water injection wells, but the pressure at the fracture tip. The injected water has a pressure gradient under the influence of percolation effect, so the bottom hole pressure will be higher. It depends on permeability and length of the fractures. The bottom hole pressure will be greater when fracture length is longer and fracture permeability is lower.

\section{CONCLUSIONS AND RECOMMENDATIONS}

1) The mechanical properties of poorly consolidated sandstone are different from consolidated and brittle rocks. Poorly consolidated sand has properties with high porosity and permeability. The form mechanism of fractures in poorly consolidated sandstone should consider fluid-solid coupling effect.

2) The fractures of poorly consolidated sandstone are induced by shear failure in the process of injecting water. The shear fractures are parallel to the radial direction (percolation direction) when the radial effective stress is the intermediate principal stress. It 
is advantageous for fracture to propagate and form high porosity-permeability belt.

3) Water injection will generate shear fractures paralleled to the maximum horizontal stress. At this time, the water injection fracture pressure is the bottom hole pressure. The fracture pressure calculated by the model established in the paper is less than that calculated by the conventional method.

\section{ACKNOWLEDGEMENTS}

This study was supported by national science and technology major projects of China (Grant No. 2016ZX05058-002-006).

\section{REFERENCES}

[1] X. Gang, "Research on sand production mechanism and prediction of loose sandstone reservoir," Beijing: China University of Petroleum (Beijing), July 2000.

[2] S. Chonghua, "A research on damage mechanisms of loose sand reservoirs during their production,” China Offshore Oil and Gas, vol. 21, pp. 31-34, Jan. 2009.

[3] B. M. Li, Z. M. Wang, and X. Liang, "Numerical simulation on sand carrying capacity in horizontal wellbore in unconsolidated sandstone heavy oil reservoir in bohai,” Petroleum Drilling Techniques, vol. 39, pp. 86-90, Mar. 2011.

[4] Y. I. Kang and P. Y. Luo, "Influence of clay minerals on formation damage in sandastone reservoir- a review and prospect," Drilling Fluid \& Completion Fluid, vol. 17, pp. 36-40, Sep. 2000.

[5] Q. Feng, S. Li, and X. Han, "Network simulation for formation impairment due to suspended particles in injected water," Journal of Petroleum Science and Engineering, vol. 133, pp. 384-391, July 2015.

[6] J. R. Wang and Z. T. Xue, "Fracture analysis and reasonable injection pressure limit definition of high pressure waterflooding well,” Petroleum Geology \& Oilfield Development in Daqing, vol. 22, pp. 32-34, May 2003

[7] Z. D. Cui, D. A. Liu, and R. S. Zeng, "Resistance of caprock to hydraulic fracturing due to $\mathrm{CO}_{2}$ injection into sand lens reservoirs," Engineering Geology, vol. 164, pp. 146-154, 2013.

[8] W. D. Liang, G. P. Jiang, and L. Y. Wang, "Establishment of reasonable water injection pressure of sandstone reservoir," Journal of Daqing Petroleum Institute, vol. 28, pp. 42-44, July 2004.

[9] D. W. Zhang and Z. Y. Zeng, "Pattern and analysis of flooding indication curves in Toutai oil field of Daqing," Journal of Daqing Petroleum Institute, vol. 26, pp. 26-27, July 2002.

[10] L. Yang, "The application of Hierarchical indicator curve in water injection optimization of Sazhong oilfield," Petroleum Geology and Engineering, vol. 28, pp. 90-92, July 2014.

[11] N. Y. Zhou and Z. Z. Yang, "Overview on pressure prediction of formation fracture," Journal of Chongqing University of Science and Technology(Natural Sciences Edition), vol. 13, pp. 36-39, Jan. 2011.

[12] Y. D. Zhu, W. Zhang, and Y. W. Liu, "The calculation model and analysis of formation fracture pressure,” Petroleum Geology and Engineering, vol. 27, pp. 92-94, Mar. 2013.

[13] R. Z. Huang, "Crack initiation and propagation of hydraulic fracturing," Petroleum Exploration and Development, vol. 15, pp. 62-67, Sep. 1998.

[14] H. K. Ge, Y. S. Lin, and S. Z. Ma, "Modification of Holbrook's fracture pressure prediction model,” Petroleum Drilling Techniques, vol. 29, pp. 20-22, May 2001.

[15] Y. M. Li, Y. C. Yue, and J. C. Guo, "A new method for fracturing pressure considering the effect of reservoir plugging," Petroleum Geology and Engineering, vol. 22, pp. 108-112, Sep. 2008.

[16] J. Sun, J. Deng, and B. Yu, "Model for fracture initiation and propagation pressure calculation in poorly consolidated sandstone during waterflooding," Journal of Natural Gas Science and Engineering, vol. 22, pp. 279-291, Jan. 2015

[17] L. Y. Chin and C. T. Montgomery, "A numerical model for simulating solid waste injection in soft rock reservoirs," in Proc. SPE Annual Technical Conference and Exhibition, 2004.

[18] S. Antonin, "Physics and modeling of themal flow and soil mechanics in unconsolidated porous media," SPE Production Engineering, pp. 47-55, 1992.

[19] K. Agarwal and M. M. Shamar, "A new approach to modeling fracture growth in unconsolidated sands," in Proc. SPE Annual Technical Conference and Exhibition, Denver, Colorado, U.S.A., 2011.

[20] M. Khodaverdian and P. McElfresh, "Hydraulic fracturing stimulation in poorly consolidated sand," Mechanisms and Consequences, 2000.

[21] C. Pater and Y. Dong, "Experimental study of hydraulic fracturing in sand as a function of stress and fluid rheology," in Proc. SPE Hydraulic Fracturing Technology Conference, Texas, USA, Jan. 29-31, 2007.

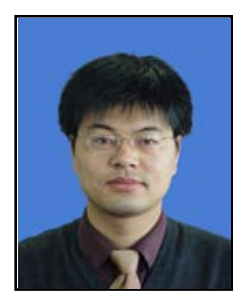

Fan Baitao was born in Henan province, China. He was born in August 16th, 1975. He got his bachelor degree in petroleum engineering in 1998 at Northeast Petroleum University, Department of Petroleum Engineering. Then he obtained the master degree in drilling engineering in 2012 at the same university. Now he is as a Ph.D candidate at China University of Petroleum (Beijing), Department of Petroleum Engineering, Beijing, China.

He is currently an expert of drilling and completion engineering in China National Offshore Oil Corporation (CNOOC), senior engineer, the manager of department of well construction and intervention in Bohai Petroleum Administration Bureau in Tianjin, China. Dr. Fan is a member of SPE.

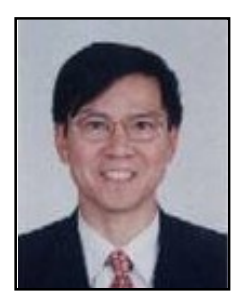

Deng Jingen was born in Jiangxi province, China. He was born in August 12th, 1963. He graduated from China University of Petroleum (Huadong) in 1983 and got his bachelor degree in petroleum engineering in Dongying, China, and then got his $\mathrm{Ph} . \mathrm{D}$ in drilling engineering in 2000 at China University of Petroleum (Beijing), Beijing, China. He is major in petroleum engineering which include water flooding development, hydraulic fracturing, sand control technique, wellbore stability.

He is currently a professor at China University of Petroleum (Beijing), Department of Petroleum Engineering, Beijing, China. Meanwhile, he is the director of CNPC well stability laboratory, the director of Science and Technology Department of China University of Petroleum (Beijing). He has written over 60 technical publications on petroleum engineering. Prof. Deng was awarded as "Changjiang Scholar" by Ministry of Education in China, and He was selected as candidate of New Century Talents Project in China. He won the top 100 outstanding doctoral dissertation winner in 2003 and the second prize of National Scientific and Technological Progress Award.

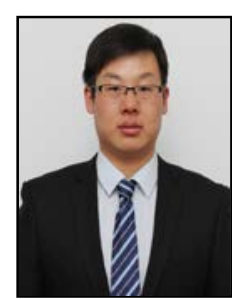

Lin Hai was born in Henan province, China. He was born in Feb. 11th,1987. He got his bachelor degree in petroleum engineering in 2011 at China University of Petroleum(Beijing), Department of Petroleum Engineering. Then he obtained the master degree in drilling engineering in 2014 at the same university, Department of Petroleum Engineering, Beijing, China.

$\mathrm{He}$ is currently an engineer of drilling engineering in China National Offshore Oil Corporation (CNOOC), Bohai research institute of Bohai Petroleum Administration Bureau in Tianjin, China. He has been involved in the areas of hydraulic fracturing, sand control, rock mechanics. 


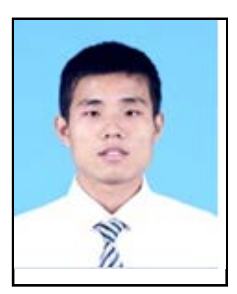

Sun Jin was born in Shandong province, China. He was born on February 17th, 1987. He got his bachelor degree in petroleum engineering in 2009 at China University of Petroleum (Huadong), Department of Petroleum Engineering, Qingdao, China. Then he obtained the master degree in drilling engineering in 2012 at the same university. And finally he got his Ph.D in 2016 at China University of Petroleum (Beijing), Department of Petroleum Engineering, Beijing, China. At present, he is major in petroleum engineering which include water flooding development, geological disasters and borehole stability.

He is now a POSTDOCTORAL FELLOW at Institute of Deep-sea Science and Engineering, Chinese Academy of Sciences since 2016 in Sanya, China. Sun is a member of Geophysical Society of China, and he also got a membership of Geophysical Society of Hainan Province of China

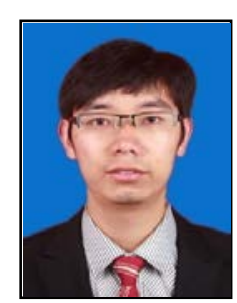

Li Jin was born on October 29, 1988, Hubei province of China. He got master's degree of oil and gas well engineering in 2015 at Southwest Petroleum University, Department of Petroleum and natural gas Engineering, Chengdu, China. At present, as a engineers worked Bohai research institute in Tianjin, China. $\mathrm{Mr} \mathrm{Li}$ is mainly engaged in the research or design of perforation technology, sand control and cement. 